\title{
Instructors' Conceptions of Reflective Learning: A Phenomenographic Study
}

\author{
Addisu Leyew Bailie ${ }^{1}$, Engida H. Gebre ${ }^{1}$ \& Kevin O’Neill ${ }^{1}$ \\ ${ }^{1}$ Faculty of Education, Simon Fraser University, Burnaby, Canada \\ Correspondence: Addisu Leyew Bailie, Faculty of Education, Simon Fraser University, 8888 University Drive, \\ Burnaby BC., V5A 1S6, Canada. Tel: 1-778-522-2060. E-mail: abailie@ sfu.ca
}

Received: October 2, 2021

Accepted: October 25, $2021 \quad$ Online Published: November 8, 2021

doi:10.5539/hes.v11n4p102

URL: https://doi.org/10.5539/hes.v11n4p102

\begin{abstract}
Reflective learning has been considered an important learning experience in higher education because of its value for personal and professional self. Despite the potential benefits, there is diverse interpretation of the meaning and process of reflective learning. Theoretical frameworks and models that purport to explain what it entails abound; however, there is a dearth of research that explores conceptions from the perspective of instructors. This study examined university instructors' conceptions of reflective learning in the context of education courses. Semi-structured interviews were employed to collect data from 32 instructors who consented to participate. The interviews were transcribed, segmented, coded and compared. Our phenomenographic analysis resulted in four qualitatively different conceptions of reflective learning: critical engagement with content, improving professional practice, identity development, and developing critical consciousness. The study has implications for faculty development and research on reflective learning.
\end{abstract}

Keywords: reflection, reflective learning, conceptions, phenomenography

\section{Introduction}

Conceptions are the lenses through which people view and interpret the world (Pratt, 1992). Research on teaching established the impacts of teachers' conceptions of teaching, learning, and knowing on their instructional decisions and processes (Kember \& Kwan, 2000; Lam \& Kember, 2006; Pajares, 1992; Pratt, 1992). A teacher's conceptions of teaching influence his/her decisions on what teaching methods to employ, what learning tasks to design, and what assessment strategies to use (Kember, 1997). Lam and Kember (2006), for instance, reported a relationship between essentialist conceptions of teaching and content-centered teaching and also between contextualist conceptions and student-centered approaches to teaching. Similarly, a conception of teaching as transmission of knowledge was found to be related to enacting content-based teaching and employing frequent tests and quizzes (Kember \& Kwan, 2000). This implies that efforts related to instructional reform would benefit from considering instructors' ways of understanding of teaching and learning because strategy-based approaches in professional development do not necessarily result in changes of instruction unless associated conceptions and intentions are addressed (Trigwell \& Prosser, 1996).

Over the last three decades, research on conceptions has largely focused on teaching and learning in general (e.g., Bruce \& Gerber, 1995; Kember, 1997; Kember \& Kwan, 2000; Pratt, 1992; Tigchelaar, Vermunt \& Brower, 2014; Säljö, 1979; Saban, Kocbeker \& Saban, 2007) or conceptions of teaching and learning in disciplinary areas (e.g., Prosser, Trigwell \& Taylor, 1994) with little attention to more specific constructs like reflective learning. Although developing learners' reflective competences has become a key objective for instructors in higher education (Colomer, Serra, Cañabate \& Bubnys, 2020), studies on their conceptions of reflective learning are scarce. Efforts to develop frameworks that facilitate our understanding of reflective leaning are either merely theoretical or are primarily based on analysis of student learning artifacts.

The complex relationship between conceptions and approaches in the general teaching and learning literature means it is imperative that efforts to foster reflective learning in higher education should begin with an understanding of instructors' conceptions. This is because the nature of learning activities selected and enacted to foster reflective learning could be related to the way instructors understand the concept (Clara, 2015). Such an understanding of instructors' conceptions is particularly important in reflective learning for it has been subjected to a wide range of interpretations in the literature. Despite considerable efforts to clarify the concept, there are 
still ambiguities regarding what reflective learning entails as well as the models that can be used to operationalize its elements. This study therefore aims to explore instructors' conceptions of reflective learning in the context of Faculty of Education in a Canadian university.

\subsection{Reflective Learning in Post-Secondary Education}

Reflective learning has been considered an important learning experience in higher education because of its value for personal and professional self. Among the often mentioned benefits for learners are enriching and furthering new knowledge and action (Brockbank \& McGill, 2002; Roessger, 2020); gaining self-awareness (Miller, 2020; Tan, 2021); supporting self-regulated and autonomous learning (Huang, 2021); promoting and cultivating transformative and lifelong learning (Brockbank \& McGill, 2002; Huang, 2021; Tan, 2021); managing the demands of multiple expectations (Ryan \& Barton, 2020); and resolving uncertainties and complexities (Chan \& Lee, 2021). More than ever, reflective learning becomes crucial in this indeterminate world that we inhabit. In the context of the current pandemic, for instance, Walpola and Lucas (2021) discussed how reflection benefits health practices. In describing the importance of reflection for medical professionals, the researchers stated, "during the COVID-19 pandemic, reflective learning practices have provided an effective and timely mechanism for practice change, which previously have had a poorer uptake by medical professionals" (Walpola \& Lucas, 2021, p. 144). They further contend that reflective learning processes enabled a better management of the pandemic by allowing professionals to use practical and timely approaches rather than rational and theory-based procedures. Reflection can "promote resiliency and resourcefulness in the face of life's dynamic challenges" (Rogers, 2001, p.55). It is therefore critical that reflective learning is fostered in higher education because it benefits students' personal development as well as their professional engagement with likely use of their skills for the benefit of society at large (Gibbons, 2019).

Despite the potential benefits, however, there is diverse interpretation of the meaning and process of reflective learning. Its meaning is "unanimously recognized in the field [of teacher education] to be ambiguous" (Clara, 2015, p.261) and vary based on time and context (Chan \& Lee, 2021). Since Dewey's initial work on reflection, scholars have been grappling with determining what reflection entails. Dewey (1933) understood reflective thought as: "active, persistent and careful consideration of any belief or supposed form of knowledge in the light of the grounds that support it and the further conclusion to which it tends" (p.9). His interpretation of reflection emphasized a way of thinking and a conscious effort of examining and inquiring one's beliefs and ideas based on evidence and rationality. After half a century of Dewey's definition, Schön's (1983; 1987) work on reflection rekindled interest and discussions among scholars engaged in professional preparation programs. The notion of reflection-in-action as an antithesis to technical rationality was central to Schon's work. That is, technical rationality, which involves "an application of knowledge to instrumental decisions" is considered incomplete to address complex, uncertain, and unique problems that professionals encounter in the real world (Schön, 1983, p.50). Schön thus proposed that reflection-in-action is "central to the art through which practitioners sometimes cope with the troublesome 'divergent' situations of practice" (p.62).

Following Schön's seminal work, the concept and practice of reflection have continued to evolve pertaining to different contexts. Rose (2013) considered the busyness of everyday life in the digital world in her definition of reflection. She understood reflection as "a form of deep thought that takes place in conditions of solitude and slowness" (p. x). She noted that reflection unfolds when people take time from the chaotic and hyper-stimulating world that precludes reflective engagement. In order to address the limitations of Schön's reflection-in-action and reflection-on-action, Rose introduced the notion of "reflection-then-action" representing a process "in which reflection comes first and informs subsequent action"; thereby best characterizing the relationship between reflection and action (Rose, 2013, p.29). Barton and Ryan (2020) also discussed reflective learning pertaining to international students learning in higher education. They provided a two-part definition that they contend is broad and generative for this group of students. They defined reflective learning as "1) making sense of experience in relation to self, others and contextual conditions; and importantly, 2) reimagining and/or planning future experience for personal, professional and social benefit" (p. 2). Their definition emphasizes the importance of transforming international students' learning and employability potentials through reflection on their beliefs and practices pertaining to cultural and professional contexts (Barton \& Ryan, 2020).

\subsection{Instructors' Conceptions}

In educational research, several related terms such as beliefs, perceptions, and theories are used to denote teachers' way of understanding and representing professional practice. The use of such terms largely depends on researchers' choice of words and their meaning (Pajares, 1992). In this study, we use the term conception as it represents a broader construct encompassing beliefs, knowledge and meanings (Barnes et al., 2017). Pratt (1992) 
defined conceptions as "specific meanings attached to phenomena which then mediate our response to situations involving those phenomena" (p. 204). Conceptions are seen as different ways of understanding a particular phenomenon (Marton \& Pong, 2005) or established generalized meanings that serve as standards of reference (Dewey, 1933). On the grounds of these descriptions, we understand conceptions as meanings individuals' assign to phenomena, experiences or issues. These meanings are personal (Pratt, 1992) and relational (Svensson, 1997) that are created from the person's interaction with the external world.

Conceptions are important in "facilitating the grasp of concrete cases of human functioning" (Marton, 1981, p.177). Hence, it is critical that we examine instructors' conceptions of reflective learning to gain insights about their understandings and related instructional strategies. Several factors such as disciplinary orientations and scholars' theoretical perspectives are attributed for the diversity of conceptualizations and models of reflective learning. For instance, Lyons (2010) interpreted the meanings of reflection based on the works of three prominent scholars on the topic. She expounded that reflection was understood as a mode of thinking, knowing and critical consciousness by Dewey, Schön and Freire respectively. Discipline wise, in professions such as teaching, nursing and social work, reflection has been mainly understood in relation to practices and actions (Fisher, 2003). The theoretical perspectives through which interpretations are made are also among the contributing factors. Conceptualizations from a critical theory stance, for example, tend to focus on power and hegemony (Brookfield, 1995; 2009). Our review of empirical studies on reflective learning also revealed conceptions ranging from conceptual understanding to examination of broader socio-cultural contexts (Authors, 2020).

In general, theoretical frameworks and models that purport to explain what reflective learning and practice entails abound. However, there is a dearth of research that explores instructors' conceptions of reflective learning in the higher education context. Similarly, although researchers have tried to map out different categories and levels of reflection, mainly based on students' artifacts of assignments and reflective tasks, studies that examine conceptions of educators who design those tasks and assignments are scarce. This study therefore builds on previous works in the field to explore the different ways professors of education understand reflective learning. Specifically, the study answers the following main question:

- What are university instructors' conceptions of reflective learning in the context of education courses?

\section{Method}

The purpose of this study was to examine instructors' conceptions of reflective learning using data from interviews with instructors at a western Canadian university. We employed a phenomenographic approach to answer our research question. Phenomenography is a research approach that aims "to investigate the qualitatively different ways in which people understand a particular phenomenon or an aspect of the world around them" (Marton \& Pong, 2005, p.335). In other words, participants' conceptions of the phenomena of interest is at the heart of phenomenographic research (Entwistle, 1997; Richardson, 1999; Tight, 2016). In this study, the phenomenon of interest is instructors' conceptions of reflective learning.

Data were collected from instructors in the Faculty of Education during three academic terms in 2020. First, instructors who were assigned to teach education courses at graduate and undergraduate levels during the data collection period were identified. Then, we selected courses that included some form of reflective learning experiences through preliminary assessment of course descriptions posted online. Such inclusion of reflective learning experiences in courses took different forms and levels such as a learning outcome/objective, assessment strategy, a program/course value or principle, etc. This helped to ensure that participants who had the experiences of the phenomena of interest are included which is considered important in phenomenographic studies (González, 2011). Instructors for courses identified in this way were invited to participate in the study. A total of 32 instructors consented to participate.

Among the instructors who participated in the study, $31.3 \%$ of them were teaching undergraduate courses, $34.4 \%$ professional development program (PDP) courses and 34.4\% graduate courses. Professional development program (PDP) is the Faculty's signature teacher education program where students are admitted after completing a bachelor's degree and trained to be teachers in elementary or secondary education. In terms of academic position, 13 were tenured/tenure-track faculty, 2 were adjunct professors, 9 were sessional instructors and 8 were faculty associates. Faculty associates are seconded K-12 teachers who are recruited by the Faculty to teach in the teacher education program. Sessional instructors are hired to teach courses on term basis.

Participants represented as much variation as possible in terms of academic positions, program areas and teaching experience. They are affiliated to different programs in the Faculty such as Curriculum Studies, Educational \& Counseling Psychology, Art Education, Mathematics Education, Language Education, Science 
Education, Educational Technology, and Educational Leadership. In terms of teaching experience in higher education, participants ranged from one to over forty years of experience. Many of the professors (tenured/tenure-track and adjunct) have more than 15 years of teaching experience in higher education. Faculty associates and sessional instructors have also several years of teaching experience either at K-12 levels or in higher education as graduate students.

Although researchers may use different data collection methods to understand participants' conceptions of phenomena, interviewing is considered as the primary method in phenomenographic research (Åkerlind, 2005; Marton, 1986). This is because interview is "the most appropriate means of obtaining a detailed and rich encounter with the lifeworld" of the participant (Ashworth \& Lucas, 2000, p. 302). Interviews allow for probing which is essential to explore the different aspects of participants' understanding and experience of the phenomena. Accordingly, we employed a semi-structured approach to interviewing that involved improvising questions and probes when appropriate and reordering and sometimes skipping questions based on the responses of the interviewees.

The general purpose of the interview was to explore their understanding of reflective learning, related instructional strategies they use to foster reflective learning and their perceptions of barriers to students' engagement in reflective learning processes. However, the data used for this study focus on their conceptions of reflective learning. Examples of interview questions that mainly helped to elicit participants' understanding of the concept include: How do you define reflective learning? What are the purposes of learning activities you designed in the course? Why is reflective learning important? What kinds of responses make you think that students have engaged in reflective learning? However, it should be noted that descriptions of conceptions can be identified from responses to other questions like instructional strategies or barriers to reflective learning and were included in the analyses of conceptions when appropriate.

Interviews were conducted both in-person and virtually. Since, most of the data were collected during the Coronavirus pandemic, phone and zoom interviews were used depending on the participants' choice. Interviews were audio-recorded and transcribed verbatim. The length of interviews ranged from 27 to 56 minutes.

Data analysis in phenomenography is an iterative process of reading and rereading through transcripts, identifying and segmenting data relevant to the research question, examining underlying meanings, and comparing and contrasting them across interview transcripts (Åkerlind, 2005; Forster, 2016; Tight, 2016). Accordingly, from the general corpus of interview transcripts, we segmented those focusing on instructors' understanding of reflective learning (our phenomena of interest) and assigned descriptive codes to the segments (Miles \& Huberman, 1994). Then, we read the transcripts multiple times to explore similarities and differences in participants' conceptions. Categories of descriptions, which are the main outcomes of phenomenographic analysis (Åkerlind, 2005; Entwistle, 1997; Svensson, 1997), are developed through constant comparison of descriptive codes along with their respective transcripts across the data set. Although the individual contexts from which the transcripts are drawn are important in understanding participants' meanings, analysis mainly focused on the collective experience to identify the range of conceptions across the whole sample (Åkerlind, 2005; Tight, 2016).

\section{Results}

Analysis of interview transcripts indicate that most of the participants' held multiple understanding of reflective learning. Their responses related to issues such as why reflective learning is important, what learning activities it involves and what students reflect upon. Based on closer examination of recurring descriptions within and across the interview transcripts, we constructed four categories of reflective learning: critical engagement with content, improving professional practice, identity development, and critical consciousness. Excerpts from transcripts are used to illustrate each category. In reporting participants' responses, alphanumeric codes are used to conceal their identities. Codes of UT, GT and PD are assigned to instructors who were teaching undergraduate, graduate, and professional development courses respectively. The different instructors' understandings of reflective learning are summarized in Table 1. This table provides a brief description of the four categories as well as excerpts as examples for each category.

\subsection{Critical Engagement with Content}

In this category, reflective learning is seen as developing an in-depth understanding of course contents. This is evident from participants' descriptions of the purposes, learning activities and objects of reflection that they provide while answering the interview questions. Whichever aspect their responses focus on, they tend to distinguish reflective learning from non-reflective learning by its focus on developing an in-depth understanding of concepts, theories, or ideas students are presented with in the courses. For example, UT12 clarifies the 
purpose of reflective learning in relation to critical thinking:

I want them to be critical thinkers. That is important. I want them to not just consume the material and eat it up and be like, oh, great this tastes good. I want them to be able to exit this class and think critically about the material. I think that higher education is not just about absorption and like spitting out an answer at the end of the day, it is about critically engaging with the ideas you are presented with.

This participant's response makes a distinction between reflective and non-reflective learning in that the former aims to bring about critical conceptual understanding and the later just focusing on rote memorization.

Table 1. Categories of conceptions of reflective learning with examples

\begin{tabular}{ll}
\hline Category & Description \\
\hline Critical & An in-depth and critical \\
engagement & intellectual engagement with \\
with content & ideas and concepts presented \\
& in the course. It entails going \\
& beyond surface learning that \\
& focuses on regurgitation of \\
& information and rather focus \\
& on conceptual understanding \\
& and analysis
\end{tabular}

Improving professional Practice

Identity Development

A tool for improving professional practice. It involves potential anticipating professional contexts and/or looking back to practice and then taking actions to improve or change the practice.

An examination of one's beliefs, biases, assumptions and experiences with the aim of becoming aware of oneself and developing one's identity

$\begin{array}{ll}\text { Critical } & \text { Examining and challenging } \\ \text { Consciousness } & \text { taken-for-granted } \\ & \text { assumptions and practices } \\ & \text { and becoming aware of how } \\ \text { broader systems and } \\ \text { structures affect one's } \\ \text { personal and professional } \\ \text { lives. }\end{array}$

\section{Example}

"the quality or the kinds of questions that provoke discussion, they are a sign rather than staying on the surface, why did the author say about this or give a quote for, so rather than those kinds of, you know, surface level questions, if they are engaging with a really in-depth question about one of the contradictions between this and that more like" (GT02)

"So, I think reflection for me is there is a part that is interpretation that is contact with ideas or with a text you read or a webinar that you listen to. So, there is a part that is being into contact with and then processing it, deciding how you understand it" (PD28)

"It [reflective learning] enables people to really take a look at their own practice, their own work in the midst of the work. And it helps them to gain insights into what they are doing, and the kinds of adjustments and changes that need to take place" (PD33)

"I think ... to bring it back on you like where are your biases, what are you feeling, how does this get in the way of your work, you know ... questioning themselves, turning the mirror back on them, which is the goal really ... you got to change yourself and your views and not just change but understand them. It does take a certain amount of like it is that reflexivity, right, to be able to develop your identity" (GT19).

"I would say, we need to have a good understanding that the development of the whole person is vitally important in our students. ... So, I think that is the first thing that we need to have that awareness that we are developing human beings here. And that development necessarily involves reflection" (GT21)

"I see it as a method for critique, but you know, like in a sort of classic theoretical sense of like, you know, challenging assumptions and challenging ideology and unpacking their social location" (UT01)

"the school is not a neutral space. There is power in the school. So the gaze is something that gives value to objects and practices, and people, and the role of teachers is to develop critical consciousness". (UT08)

Another participant (GT04) also explained the main goal of her course as conceptual development and reflective learning as key to the realization of such goal. She stated:

All I do in my classes I said that my goal is conceptual development of my students. So, in my world, if I 
will help students to develop conceptually, with that alone, it is impossible without them honing this reflectively and metacognitively. My care is conceptual development, it is not personalized yet. I would recommend not to personalize education because it is not about persons but conceptual development (GT04).

In her 'theory' of concept development, this participant contends that concepts are systemic and cannot be developed unless one possesses a reflective capacity. The participant focused on describing personalized (or not) education to express her dissent from views of reflective learning as personal reactions and feelings. When asked about the kind of student responses or activities that make her think students are engaged in reflective learning, her reply also focused on the depth of thought and understanding students develop about the course materials they were presented with.

Well, it is very clear that the students' responses will show clearly stating their argument about the complicated concept, not the ones who just sort of done overnight, but the ones who took a lot of time to prepare to elaborate on the research literature for supporting the argument. And then once they get to that level of sort of attaining these concepts, they also become sort of attached to it because it is a lot of intellectual labor (GT04).

In critical engagement with content, there is also a greater focus on nature of learning activities in participants' descriptions of reflective learning. Most participants reported critical reading and thinking as well as reviewing experience as important facets of activities that they regard as reflective learning. When they described learning activities that represent reflective learning, participants often made a reference to the level of students' task-related cognitive engagement. Such descriptions reinforce the features of this category because the focus is on criticality and depth in thinking pertaining to the course content. PD26's comparison of reflective and non-reflective learning activities clearly illustrates this idea.

I feel like when they are not just regurgitating what they heard or saw, but when they are commenting on what they heard, or saw, or bringing it back to how it connects to them ... I think, you know, when they are not [reflecting], it is just kind of seems very surface, it seems like yeah, there is nothing new here. There is nothing to show that they have sort of chewed it up a bit and have really tried to wrestle with whatever they have come up with (PD26).

GT07's description of his students' reflective capacity and development is also indicative of the level of thought as a distinguishing feature of reflective learning. He stated that students' reflective capacity has developed over the duration of the course as they were responding to each other in more engaging ways and asking more meaningful questions rather than simply complementing to each other. The following excerpt is from a participant who was describing the changes she made on the learning activities to foster reflective learning.

I want to give them a slightly different experience. So, I cut back a little bit on the regular writing. So sometimes I like to have critical reading responses as ongoing thing so that I get a sense but also the students are able to integrate their learning and their reading throughout the semester (GT02).

The point that the above excerpt demonstrates is that reflective learning activities are seen as involving synthesis of ideas from reading materials which is distinct from "regular" writing involving descriptive summary of the readings. Whether students are tasked with reading, writing, questioning, or responding activities, depth and criticality are central to the meaning of reflection. In other words, this conception incorporates learning activities involving way of thinking that goes beyond the surface level and obvious observation.

The other focus is on engaging students in reviewing and relating experience to promote depth and criticality in content learning. UT12, for instance, emphasizes the importance of reviewing one's learning experience and yet with the aim of checking on their understanding of the content they have learned:

I think it is very important that students have the opportunity to reflect back on how they have developed in the term, how they are under to kind of hold a mirror up to their understanding of the coursework, you know they are reading these articles every week or doing the modules, and the quiz feedback, that is one way that they get a reflection of how they were doing.

The emphasis on course readings, concepts and ideas as objects of reflection is also another manifestation of the view of reflective learning as critical engagement with content. Although subject matter content could be the starting point for all other categories of conceptions, it is seen as the main target of reflective learning by some participants. When asked about the meaning of reflective learning, PD27's responses emphasized two types of objects of reflection, of which subject matter content is one.

So, I think I guess what I am saying here is I think there is sort of two aspects. One is, I think it is important 
for them to reflect on the ideas that are being presented to them. And then, it is important for them to reflect on their own worldviews that have shaped them in various ways, their own worldview and experiences (PD27).

Speaking about the differences in the nature of reflective learning in different programs, GT02, a professor who was teaching a graduate course, pointed out that reflective learning in her course targets the contents of the material or course.

I have to sort of insist that no, this is not about writing your feelings. This is about the material, so there are multiple different kinds of reflection activities. And so, I think, depending on the purpose of a particular program of study. So, in PDP or in teacher education, we engage in more reflective practice in reflecting on one's practice. In, say a graduate or an undergraduate course, we depending again on the area of study, so philosophy of education would be very different than sociology of education, where we encourage students to think about the material aspects (GT02).

Indeed, the participant is explaining how reflective learning can be understood differently based on the nature and goals of the programs. More specifically, she distinguished what students in teacher education programs and other education courses reflect upon. Whereas practice and feelings are targeted in teacher education courses, subject matter content is the primary focus of other education courses including her own.

In general, reflective learning in this category is seen as critically engaging with knowledge or subject matter content in the discipline with the goal of enhancing students' conceptual understanding. The level of understanding that students are expected to develop might be described using different modifiers such as critical, in-depth, understanding, etc. However, their common facet is that it is distinct from rote retention of contents. This perspective is related to what is commonly known as deep versus surface approaches to learning. That is, reflective learning is seen as a deep approach that involves "critically interacting with the content, relating ideas to previous knowledge and experience, and focusing on the content's underlying meaning to achieve learning with understanding" (Huang, 2021, p.41). On the other hand, learning activities that are seen as non-reflective adopt a surface approach characterized by memorization and reproduction of content.

\subsection{Improving Professional Practice}

In this category, reflective learning is understood in terms of bringing about changes in one's practice or deliberating on how it should be improved. It is seen as a tool for solving problems of professional practice. In most cases, participants made a reference to teaching practice when explaining their perspectives of reflection. The following excerpts from two participants' responses to questions on why reflective learning is important clearly demonstrates this conception.

If I do not take the time to reflect, then I could keep doing that same thing that is not working. Or I could accidentally keep doing the same thing and not realize why it is working. So, then I do not try to figure out what else I need to bring back in. ... So obviously, and if we do not examine things, we could be in danger of replicating things that maybe are not so good. So, we need to take that time to look at what we are doing and think about the why I am doing what I am doing (PD26).

This idea that we are always needing to be responsive to the students who are in front of us and view each sort of teaching moment is a new moment. I think that there are things that are both, you know, the reflection on practice is one thing but the reflection for practice and looking into the future [is another thing]. I think it just keeps the profession alive, whether you are in higher education or in $\mathrm{K}$ to 12. And yeah, I don't know, I'd say it is hard for me to separate it from a good teaching, period (PD32).

Participants were focused on developing professional practice for which students are preparing for. This view of reflective learning as improving practice or solving problems of professional practice was seen in two ways: a) anticipating what will happen in future practice and planning accordingly, and b) reviewing and reflecting on one's practical experience. These two perspectives are evident from GT06's notions of "preflection" (participant's terminology for anticipatory reflection) and reflection pertaining to his immersive model of course design. Describing the immersive model, this participant noted that his graduate students first engage in a K-12 lesson (i.e., they take the role of K-12 learners and the professor as K-12 teacher) in a subject that they are preparing to teach and then followed by discussions on theories and concepts. Thus, preflection entails examining the application of what they have experienced and discussed in the course to professional (school) contexts. The instructor explained the importance of preflection as:

One of the things that is important for me is not only reflection, but preflection. So preflection, for me, is where we discuss something in class, they have experienced something and then I may ask them to 
anticipate how this will work in their classroom. Where will the challenges be? Which students will respond well, which students won't? Those sorts of things of anticipating and resolving issues before they actually happen is and sort of cementing their commitment to things through preflection, to me is an important thing (GT06).

Such anticipatory reflection is considered crucial for addressing new and original problems (Wilson, 2008). Reflective learning as a tool for solving professional problems also entails looking back to practice and improving it based on the review. This perspective is illustrated by GT06, who provided his definition of reflection as:

I think I would define reflection the same way [as Donald Schon]. So, for me reflection is to think back on your actions, to think back on the results of those actions, and try to build a link between my actions and the results of the action. So, my action is my teaching. The reaction is the learning or the student behavior and to think about those things. And Donald Schon asked us to think about those things with an explicit purpose of using that sort of feedback cycle as a way to change your actions (GT06).

In this category, reflective learning is seen as a tool for improving not only the practice of individuals but also the community of professionals at large. PD31's response to the question on the importance of reflective learning reinforces the perspective of reflection as a process of reviewing practice to solve problems. He stated:

It is really important because ... when a school is faced with a serious problem, it is just that community of educators, brainstorming solutions on the basis of however many ways they can view the problem, that is generally how we address these things. So having them understand even this early in the semester in the program, having them come to an understanding of the community of educators, that they are becoming a part of the professional community that they are joining (PD31).

In the context of professional development, this category also embraces the notion of reflective learning as a lifelong learning strategy that professionals use to keep abreast of the demands of their profession. The excerpt from the following participant illustrates such conception.

So, what I've told my students in the past about the why reflection is important for teachers throughout their career is that they will leave their teacher certification program with some useful skills and knowledge. But they will be expected to continue to refine their practice over a period of 20 years or more. And, they will have to learn new things because society is a moving target, it presents new challenges all the time. And essentially, teachers have very little other than by way of resources to meet those challenges other than their own intellect and the intellect of their fellow teachers in a school. And so, reflection is important because they have to be continuously learning about all of these new challenges that they face, or new ways of addressing old challenges (PD31).

In general, the conception of reflective learning as a tool for solving problems and improving professional practice is distinct from the previous category. It is conceivable that students who developed an in-depth understanding of course content may use their knowledge to improve practice. However, in the previous category, the primary purpose of reflective learning is not to translate theory into action but rather to grasp content and improve understanding of concepts. On the other hand, practice driven purposes and views target changes in action through reflection. The emphasis in this category is on reflective learning as examination of professional practice such as teaching and the reconsideration of how it is being done and/or how it can be improved.

\subsection{Identity Development}

In this category, reflective learning is crucial for students' identity development. Palmer (2017) described identity as "an evolving nexus where all the forces that constitute [one's] life converge in the mystery of self" (p.13). Participants' reference to identity may be specific to their professional identity related to the program they are attending or generally to their personal identity. For instance, UT30 described the purposes of reflective learning that combines both personal and professional identity development. She stated:

I say to them, what I want you to develop, and what I want you to understand is, who you are as a person has everything to do and or who you believe you are as a person has everything to do with who you are going to be in that classroom. So, it is about thinking about what kind of person do I want to be in this world, to everyone, to my family, to people I do not know. Because education is fundamentally about identity formation (UT30).

In the above excerpt, one can notice the phrases ('what I want you', 'who you are', 'what you believe you are', what kind of person I want to be') that communicate how UT30 values identity as an overarching theme that guides what students are going to do both in professional and personal life contexts. Hence, reflective learning 
experiences are considered as promoting the development of one's identity. Although the concept of identity in general and professional identity in particular is complex and dynamic, an aspect of professional identity can be seen in terms of one's unique approaches and philosophies of professional practice (Walkington, 2005). An instructor of a graduate leadership course, for example, explained how reflective engagement can help students develop personal leadership approaches:

When you are thinking about self-reflection, you know, it helps to develop an awareness of personal approaches. That is what this course does to leadership in and relates it to education and profession, professional expertise. It allows you to share, to contrast personal styles of leadership to reflect and to look at strengths and some of those challenges and leadership theories and also your own personal leadership skills (GT17).

As Palmer (2017) noted, identity constitutes not only one's strengths, potentials, and good deeds, but also weaknesses, limits, wounds, fears, and biases. In most of the responses that belong to this category, identity development begins from self-awareness. But different layers could be identified from this general conception. In some cases, reflection is becoming aware of what one is doing, either during learning or professional practice. For others, the focus of awareness is about one's prior beliefs, biases and experiences. Still for others, the focus of awareness is on how they are implicated on the social space they occupy or being aware of their influences on others. What ties all these descriptions together is that reflective learning is seen as helping students become aware of and develop their personal and/or professional identities. The following excerpts from transcripts typify this conception of reflective learning as developing self-awareness.

I have sort of elucidated here that we need to have this understanding if we are going to be good professionals, we know that we really need to know who we are. And you know, this goes beyond educational professionals. This applies to any professional, having a deep sense of self and an understanding of oneself is critical in any role (GT21).

I think coming to know oneself is a big part of maturing as a human being. That is a big part of a valuable education. I think we are seeing now more than ever, what can happen when people do not do that, you know, politically with what is going on right now, we are seeing all the dangers, many of the dangers of what can happen when people do not reflect honestly. And so, to be aware of oneself is a really big thing (UT15).

For me, everything has to do with identity. And so therefore, in order for us to learn anything. We have to think about our identity. And in order to do that, it is fundamentally about reflexivity. I cannot teach you who you are as a person. Identity theory is about you coming to your own meta understandings of who you are in this world. So fundamentally the only way you can get at that is critical reflexivity, asking the hard questions (UT30).

The focus on self-awareness and identity development implies that the self becomes the main object of the reflective process. PD25 distinguished reflective and non-reflective learning based on the objects of learning and emphasizing that reflective learning targets the self. She explained about the inward-looking nature of reflective learning in her course:

So, I think that when the course, the program ran with reflection, that we often, at the end of the semester, and after we finished all the eportfolio, we have half our conference now, roughly everybody has about half our conference with each student. It is like emotionally draining because we are sometimes half therapist, half social workers, half instructors, because it brings out very deep aspects of who they are (PD25).

In general, education is seen as a process of identity development and reflection playing a critical role in the process. This conception differs from the previous category that targets change or improvement by examining what works and what did not as well as the techniques and strategies that can be applied to improve professional practice. The focus here is rather on guiding students on an inner journey toward self-awareness which is crucial to one's life, both personal and professional. This relates to Palmer's (2017) fundamental thesis in his influential book, The Courage to Teach: Exploring the Inner Landscape of a Teacher's Life, that "identity and integrity are more fundamental to good teaching than technique" (p.12). That is, answering the question of "who teaches" is more important than the "what", "how" and "why" questions in teaching and education (Palmer, 2017, p.4).

\subsection{Developing Critical Consciousness}

Critical consciousness is understood as "learning to perceive social, political, and economic contradictions, and to take action against oppressive elements of reality" (Freire, 1970, p.35). In some instances, participants viewed reflective learning as a way of creating such critical awareness of concerning societal issues. Becoming aware of 
issues like privilege, oppression, crisis, hegemony feature strongly in this conception of reflective learning. For instance, the following excerpt from UT08 indicate that she aims to help her students become aware of power dynamics as well as hegemonic ideas and structures that affect their lives.

So, since this is an education course, it is connected, I show them, I hope that at the end of the course, they get the sense of how they are part of a history of a conversation that has been going on for a long, long time, and because they are interested in power dynamics, I mean, I tried to introduce the idea of the hegemony, right? So, I guess that is what I do for that course (UT08).

This same participant explains how the goal of developing awareness about critical social issues such as power was approached in her two courses differently.

I still bring that idea that there is a power structure that permeates any educational space. So, making students aware of that in [course that she is teaching] is a little more explicit. But in [another course she is teaching], making people aware of how their voice is positioned is a little more subtle, but [creating] the sense that this is not neutral space (UT08).

What differentiates this category of conception of reflective learning from the previous categories is that it aims to help students become conscious of more subtle, complex, and broader systems and structures and the effects this might have on their own lives. The following excerpt from a participant who compares his initial response with a later during the interview indicates the distinctions between the notions of reflective learning as self-awareness and as critical consciousness.

Well, I, at the outset I talked about awareness is being a word that I gravitate more to. So, I do feel the difficulty with the word reflective in that it can become a bit self-absorbed as if it is enough for a teacher simply to be aware of themselves and nothing else. Now, I do not think that is the intent of reflective learning, right. ... the awareness that it seems to me of greatest values is this much more inclusive awareness where you are asking similar sort of reflective questions, not only of what happens in the classroom, but what is going on outside the classroom, what is going on in the lives of my students? (GT03)

Empowering students to be more conscious of the world they are living in so that they protect themselves from exploitative and oppressive practices is another example that belongs to this category. This is at least in part explained by an excerpt from the transcript of UT05.

When I see the social context in general, be it political situation in different countries and the increasing dominance of populist views especially, you know, those who have alienating views, to some extent, I want students to develop reflection so that they won't be taken advantage of by interest groups.

Similarly, UT01 spoke of the way he understood reflective learning as a "political project" with the aim of making students aware of hegemonic structures and systems in the society. Taking the university in which he was working in as an example, the participant explained the crucial purpose that reflective learning could serve in such project.

I mean, to me it's a political project, particularly in a context of privilege, but I think like, in a context of an institution like [this University], which I would describe as a more white supremacist institution, or at least like white fragile institution, and the education system as a whole within this sort of settler colonial structure that sort of operates in it, I think, like reflective learning as a way to get students to think more clearly about those systems that operate in their lives (UT01).

This instructor also illustrated the view of reflective learning as critical consciousness by sharing his expectations from students' reflective responses. When asked about the kind of student activities or responses that made him think that students were engaged in reflective learning, he replied:

Identifying oppression and oppressors. In terms of what I'm looking for, what I see is like, effective reflection is, I mean, it is just like, I am more interested in seeing them showing a critical, you know, kind of a meta, like an ability to see their own lives within social systems. But there is a danger there. Which is that there is kind of a danger of like, I have a sort of fetishizing a certain type of reflection, like a certain type of reflection comes off as more authentic or more meaningful. If it doesn't, I'm very conscious I might have a fear that I have a pattern that I'm expecting. So, I mean, like to oversimplify it, I think like students who are able to examine their own privilege or name their own oppressors are more likely to see that as meaningfully reflective.

In general, reflective learning seen as critical consciousness focuses on challenging and uncovering systems and structures that affect their personal and professional lives. The reflective process targets larger institutional, 
social, cultural and political systems with the aim of developing critical awareness about the effects that these systems and structures have on individuals and the society at large.

\section{Discussion}

The purpose of this study was to examine education instructors' ways of understanding reflective learning. Our analysis resulted in four different ways that instructors of education courses understand reflective learning. In the first category, reflective learning is viewed as involving critically interacting with course content students are presented with. While targeting the content, the process may involve critical reading responses, interpretation of the meaning of content, and relating ideas and theories to personal experience and knowledge. The primary aim in this category is to enhance students' understanding of the content dealt in the course. In the second category, improving professional practice, reflective learning targets professional practice. Through both anticipatory and retrospective reflection, the aim is to improve one's practice such as teaching. Identity development characterizes the third conception of reflective learning. In this category, the process of reflection involves examining one's background experiences, biases, assumptions, strengths, and weaknesses with the aim of becoming aware of oneself and developing their professional and personal identity. The fourth category focuses on broader systems and structures with the purpose of developing critical consciousness about how they affect the lives of individuals and groups.

A closer examination of the identified categories reveals two important issues. The first is the importance of reflection both as a tool and outcome of learning. Reflection is used as a means of facilitating the understanding of learning materials better, improving professional practice and developing one's personal and professional identity. Being able to reflect is also an expected outcome of learning in higher education. The second issue is that while the four conceptions identified in this study are not mutually exclusive (because in some cases responses from the same instructor were coded into more than one category), we contend that the conceptions become broader and more holistic as we move from the first to the last in the order of presentation. At one end, reflective learning as critical engagement with content relates to Jay and Johnson's (2002) "descriptive reflection" as well as entails considering theory and concepts in relation to personal experience. The main focus, however, is understanding the salient features of a topic or an issue and finding significance in it (Kember et al., 2000). At the other end is reflective learning as critical consciousness where the goal is understanding and challenging broader, systemic issues where the result might not be as immediate. This relates to Ward and McCotter's (2004) notion of "transformative reflection" and Merizow's (1991) "premise reflection" where learners are primed to challenge taken for granted assumptions.

No prior study came up with the four categories of conceptions reported in this study. However, individual categories relate to similar findings elsewhere. For example, in addition to the ones mentioned above, our second category, improving professional practice, is consistent with van Manen's (1977) "practical reflection" that focuses on making informed choices with the purpose of improving professional practice. Similarly, our "identity development" relates to Grossman's (2009) self-authorship reflection in terms of the object of reflection, i.e., looking inward. However, whereas Grossman's self-authorship focuses on analyzing and understanding the effects of inner experiences on one's emotions and actions, reflective learning as identity development is more holistic and emphasizes achieving integrity of the self.

The categories we identified are useful in that not only are they based on empirical data from instructors, but they also have practical significance given the sensitive and often complex nature of the context prospective professionals join after graduation. For instance, being able to understand content and evaluating credibility of sources is important for teachers as they educate the young generation to be critical in their thinking and reasoning, especially in the face of misinformation and disinformation. It is also essential that professionals not only look back and improve their practice but also determine their position in society and the positive role they can play be it in terms of training the youth or participating in voting and public service (Feldman, 2009). The contemporary world demands us much more than understanding subject matter content and applying scientific theories to professional practice. The corona virus pandemic has taught us how societal issues affect every individual's personal and professional life. Besides, issues of social justice are dominant in the current North American climate and developing critical consciousness helps to understand issue of oppression and discrimination.

Three issues are worth considering for future study. The first is that while the four categories identified in this study are timely and of practical relevance, we don't know much about specific instructional approaches and strategies for developing these conceptions as learning outcomes for students. This boils down to the issue of learning design. How do we design learning environments to engage education students in reflective learning 
and develop their skills? The second issue is the question of transfer of learning. That is, how much of their learning do prospective graduates transfer to their professional practice? Part of such transfer depends on the relevance they see for their profession in the context of their workplace and environment. The third relates to the diversity of students in higher education. Canadian institutions host hundreds of thousands of international students. These students bring unique backgrounds, experiences, and perspectives to the learning environment. Hence, teaching and learning approaches in general and reflective learning pedagogy in particular should consider the needs of international students. Due to their cultural backgrounds, they may take a different approach to reflective learning (Ryan \& Barton, 2020). This also points to the need for examining conceptions of and engagement in reflective learning in relation to student background.

\section{References}

Åkerlind, G. S. (2005). Variation and commonality in phenomenographic research methods. Higher Education Research \& Development, 24(4), 321-334. https://doi.org/10.1080/07294360500284672

Ashworth, P., \& Lucas, U. (2000). Achieving empathy and engagement: A practical approach to the design, conduct and reporting of phenomenographic research. Studies in Higher Education, 25(3), 295-308. https://doi.org/10.1080/713696153

Barnes, N., Fives, H., \& Dacey, C. M. (2017). U.S. teachers' conceptions of the purposes of assessment. Teaching and Teacher Education, 65, 107-116. https://doi.org/10.1016/j.tate.2017.02.017

Barton, G., \& Ryan, M. (2020). What does reflection look and feel like for international students? An exploration of reflective thinking, reflexivity and employability. Journal of International Students, 10(S2), 1-16. https://doi.org/10.32674/jis.v10iS2.2848

Brockbank, A., \& McGill, I. (2002). Reflective learning in practice. https://doi-org.proxy.lib.sfu.ca/10.4324/9781315604268

Brookfield, S. (1995). Becoming a critically reflective teacher. San Francisco: Jossey-Bass.

Brookfield, S. (2009). The concept of critical reflection: Promises and contradictions. European Journal of Social Work, 12(3), 293-304. https://doi.org/10.1080/13691450902945215

Bruce, C., \& Gerber, R. (1995). Towards university lecturers' conceptions of student learning. Higher Education, 29, 443-458. https://doi.org/10.1007/BF01383962

Chan, C. K. Y., \& Lee, K. K. W. (2021). Reflection literacy: A multilevel perspective on the challenges of using reflections in higher education through a comprehensive literature review. Educational Research Review, 32, 100376. https://doi.org/10.1016/j.edurev.2020.100376

Clarà, M. (2015). What is reflection? Looking for clarity in an ambiguous notion. Journal of Teacher Education, 66(3), 261-271. https://doi.org/10.1177/0022487114552028

Colomer, J., Serra, T., Cañabate, D., \& Bubnys, R. (2020). Reflective learning in higher education: Active methodologies for transformative practices [Editorial]. Sustainability, 12, 3827. https://doi.org/10.3390/su12093827

Dewey, J. (1933). How we think: A restatement of the relation of reflective thinking to the educative process. Boston, MA: D. C. Heath.

Entwistle, N. (1997). Introduction: Phenomenography in higher education. Higher Education Research \& Development, 16(2), 127-134. https://doi.org/10.1080/0729436970160202

Feldman, R. (2009). Thinking, reasoning and education. In H. Siegel (Ed.), The Oxford Handbook of Philosophy of Education (pp. 67-82). Oxford University Press. https://doi.org/10.1093/oxfordhb/9780195312881.003.0005

Fisher, K. (2003). Demystifying critical reflection: Defining criteria for assessment. Higher Education Research \& Development, 22(3), 313-325. https://doi.org/10.1080/0729436032000145167

Forster, M. (2016). Phenomenography: A methodology for information literacy research. Journal of Librarianship and Information Science, 48(4), 353-362. https://doi.org/10.1177/0961000614566481

Freire, P. (1970). Pedagogy of the oppressed. New York: Continuum.

Gibbons, J. (2019). Reflection, realignment and refraction: Bernstein's evaluative rules and the summative assessment of reflective practice in a problem-based learning programme. Teaching in Higher Education, 24(7), 834-849. https://doi.org/10.1080/13562517.2018.1514374 
González, C. (2011). Extending research on 'conceptions of teaching': Commonalities and differences in recent investigations. Teaching in Higher Education, 16(1), 65-80. https://doi.org/10.1080/13562517.2010.507302

Grossman, R. (2009). Structures for facilitating student reflection. College Teaching, 57(1), 15-22. https://doi.org/10.3200/CTCH.57.1.15-22

Huang, L. (2021). Improving learner reflection for TESOL: Pedagogical strategies to support reflective learning. New York: Routledge. https://doi.org/10.4324/9780429352836

Jay, J., \& Johnson, K. (2002). Capturing complexity: A typology of reflective practice for teacher education. Teaching and Teacher Education, 18, 73-85. https://doi.org/10.1016/S0742-051X(01)00051-8

Kember, D. (1997). A reconceptualisation of the research into university academics' conceptions of teaching. Learning and Instruction, 7(3), 255-275. https://doi.org/10.1016/S0959-4752(96)00028-X

Kember, D., \& Kwan, K. (2000). Lecturers' approaches to teaching and their relationship to conceptions of good teaching. Instructional Science, 28, 469-490. https://doi.org/10.1023/A:1026569608656

Kember, D., Leung, D., Jones, A., Loke, A. Y., McKay, J., Sinclair, K., Tse, H., Webb, C., Wong, F., Wong, M., \& Yeung, E. (2000). Development of a questionnaire to measure the level of reflective thinking. Assessment \& Evaluation in Higher Education, 25(4), 381-395. https://doi.org/10.1080/713611442

Lam, B., \& Kember, D. (2006). The relationship between conceptions of teaching and approaches to teaching, Teachers and Teaching: Theory and practice, 12(6), 693-713. https://doi.org/10.1080/13540600601029744

Lyons, N. (2010). Reflection and reflective inquiry: Critical issues, evolving conceptualizations, contemporary claims and future possibilities. In N. Lyons (Ed.), Handbook of Reflection and Reflective Inquiry Mapping a Way of Knowing for Professional Reflective Inquiry (pp.3-22). Springer. https://doi.org/10.1007/978-0-387-85744-2_1

Marton, F. (1981). Phenomenography - Describing conceptions of the world around us. Instructional Science, 10, 177-200. https://doi.org/10.1007/BF00132516

Marton, F. (1986). Phenomenography-A research approach to investigating different understandings of reality. Journal of Thought, 21(3), 28-49. https://www.jstor.org/stable/42589189

Marton, F., \& Pong, W.Y. (2005). On the unit of description in phenomenography. Higher Education Research \& Development, 24(4), 335-348. https://doi.org/10.1080/07294360500284706

Merizow, J. (1991). Transformative dimensions of adult learning. San Francisco: Jossey-Bass

Miles, M. B., \& Huberman, A. M. (1994). Qualitative data analysis: An expanded sourcebook. Thousand Oaks, CA: Sage Publications.

Miller, J. P. (2020). Finding truth within: Exploring the importance of reflective practice in deepening self-knowledge. Integral Review, 16(1), 357-390.

Pajares, M. F. (1992). Teachers' beliefs and educational research: Cleaning up a messy construct. Review of Educational Research, 62(3), 307-332. https://doi.org/10.3102/00346543062003307

Palmer, P. J. (2017). The courage to teach: Exploring the inner landscape of a teacher's life: Vol. Twentieth anniversary edition. Jossey-Bass.

Pratt, D. (1992). Conceptions of teaching. Adult Education Quarterly, 42(4), 203-220. https://doi.org/10.1177/074171369204200401

Prosser, M., Keith Trigwell, K., \& Taylor, P. (1994). A phenomenographic study of academics' conceptions of science learning and teaching. Learning and Instruction, 4, 217-231. https://doi.org/10.1016/0959-4752(94)90024-8

Richardson, J. T. E. (1999). The concepts and methods of phenomenographic research. Review of Educational Research, 69(1), 53-82. https://doi.org/10.3102/00346543069001053

Roessger, K. M. (2020). Assessment strategies for reflective learning in the workplace: A pragmatic approach. Adult Learning, 31(4), 175-184. https://doi.org/10.1177/1045159520941947

Rogers, R. (2001). Reflection in Higher Education: A Concept Analysis. Innovative Higher Education, 26(1), 37-57. https://doi.org/10.1023/A:1010986404527

Rose, E. (2013). On reflection: An essay on technology, education, and the status of thought in the twenty-first century. Toronto: Canadian Scholars' Press Inc. 
Ryan, M., \& Barton, G. (2020). International students, reflection, and employability [Editorial]. Journal of International Students, 10(S2), i-v. https://doi.org/10.32674/jis.v1

Saban, A., Kocbeker, B. N., \& Saban, A. (2007). Prospective teachers' conceptions of teaching and learning revealed through metaphor analysis. Learning and Instruction, 17, 123-139. https://doi.org/10.1016/j.learninstruc.2007.01.003

Säljö, R. (1979). Learning about Learning. Higher Education, 8(4), 443-451. Retrieved from https://doi.org/10.1007/BF01680533

Schön, D. (1983). The reflective practitioner: How professionals think in action. Basic Books

Schön, D. (1987). Educating the reflective practitioner: Toward a new design for teaching and learning in the professions. Jossey Bass.

Svensson, L. (1997). Theoretical foundations of phenomenography. Higher Education Research \& Development, 16(2), 159-171. https://doi.org/10.1080/0729436970160204

Tan, S. Y. (2021). Reflective learning? Understanding the student perspective in higher education. Educational Research, 63(2), 229-243. https://doi.org/10.1080/00131881.2021.1917303

Tigchelaar, A., Vermunt, J. D., \& Brouwer, N. (2014). Patterns of development in second-career teachers' conceptions of teaching and learning. Teaching and Teacher Education, 41, 111-120. http://dx.doi.org/10.1016/j.tate.2014.03.008

Tight, M. (2016). Phenomenography: The development and application of an innovative research design in higher education research. International Journal of Social Research Methodology, 19(3), 319-338. https://doi.org/10.1016/j.tate.2014.03.008

Trigwell, K., \& Prosser, M. (1996). Congruence between intention and strategy in university science teachers' approaches to teaching. Higher Education, 32, 77-87. https://doi.org/10.1007/BF00139219

van Manen, M. (1977). Linking ways of knowing with ways of being practical. Curriculum Inquiry, 6(3), 205-228. https://doi.org/10.1080/03626784.1977.11075533

Walkington, J. (2005). Becoming a teacher: Encouraging development of teacher identity through reflective practice. Asia-Pacific Journal of Teacher Education, 33(1), 53-64, https://doi.org/10.1080/1359866052000341124

Walpola, R., \& Lucas, C. (2021). Reflective practice: The essential competency for health systems and healthcare practitioners during the COVID-19 pandemic. Reflective Practice, 22(2), 143-146. https://doi.org/10.1080/14623943.2020.1860925

Ward, J. R., \& McCotter, S. S. (2004). Reflection as a visible outcome for preservice teachers. Teaching and Teacher Education, 20, 243-257. https://doi.org/10.1016/j.tate.2004.02.004

Wilson, J. P. (2008). Reflecting-on-the-future: A chronological consideration of reflective practice. Reflective Practice, 9(2), 177-184. https://doi.org/10.1080/14623940802005525

\section{Copyrights}

Copyright for this article is retained by the author(s), with first publication rights granted to the journal.

This is an open-access article distributed under the terms and conditions of the Creative Commons Attribution license (http://creativecommons.org/licenses/by/4.0/). 